\title{
SHALLOW 3-D REFLECTION SEISMIC SURVEYING OF GLACIAL SEDIMENTS IN THE SWISS MOLASSE BASIN
}

\author{
Büker, F., Horstmeyer, H. and Green, A.G. \\ Institute of Geophysics, ETH Zürich, Switzerland
}

\begin{abstract}
INTRODUCTION
Applications of geophysical methods to resolve diverse engineering and environmental problems have become increasingly common over the past few years. Investigations of shallow targets in complex heterogeneous geological settings require methods capable of providing high-resolution information. Although seismic reflection profiling has often been applied successfully in nearsurface studies, reliable knowledge of the true dip and lateral extent of structures cannot be obtained from sparse 2-D seismic data sets alone (Lanz et al., 1996). In order to map the stratigraphy and three-dimensional distribution of unconsolidated surficial sediments a 3-D highresolution reflection seismic survey has recently been conducted within the Suhre Valley, central Switzerland.
\end{abstract}

\section{DATA ACQUISITION}

Three-dimensional survey design was based on experiences gained from the acquisition, processing and interpretation of crossing 2-D seismic profiles in the same region (Büker et al., 1997). Seismic data were recorded across an area of $360 \mathrm{~m} \mathrm{x} 410 \mathrm{~m}$ using a shotgun source and single $30 \mathrm{~Hz}$ geophones. A nominal fold of $>50$ was achieved by recording data with two $120-$ channel 24-bit Bison seismographs. Deploying sources and receivers on a dense grid of $3 \mathrm{~m} \times 3$ $\mathrm{m}$ resulted in source-receiver offsets and azimuthal distributions appropriate for reliable mapping of sedimentary structures in the depth range 20 to $200 \mathrm{~m}$ (Büker et al., 1996). The subsurface sampling interval was $1.5 \mathrm{~m} \times 1.5 \mathrm{~m}$. A minimum number of 7 near-offset traces (i.e. source-receiver distances $<20 \mathrm{~m}$ ) and minimum offsets of no greater than $7.5 \mathrm{~m}$ was realized for most common midpoint (CMP) bins of the covered area.

\section{PROCESSING}

Processing was performed on workstations using commercial seismic software. Data quality is generally good. Low ambient noise levels (Fig. 1a) allowed first arrivals to be automatically picked using neural network routines. A summary of the applied processing steps is listed in Table 1. As for many shallow seismic reflection data sets, various types of source-generated noise (e.g. guided, surface and air waves; Robertson et al., 1996) are superimposed on the nearsurface reflections; very shallow reflections are rarely visible on the raw data. Following the first arrivals on the near-offset traces are a dominant series of subparallel and low frequency reverberations (Fig. 1a). After testing different processing operations that included bandpass filtering, spectral balancing, deconvolution, and $\tau$-p filtering, significant enhancement of reflected signals relative to the reverberations was eventually accomplished (Figs. $1 \mathrm{~b}$ and $1 \mathrm{c})$. In order to avoid mis-processing and mis-interpretating shallow signals due to erroneous stacking of first arrivals and guided waves, carefully selected top mute functions were applied to the data (Fig. 1d). Normal moveout (NMO) corrections were based on staking velocities derived from semblance analyses and constant velocity stacks. Stacking velocities ranged from $\sim 1400 \mathrm{~m} / \mathrm{s}$ for the shallowest reflections to $1900-2200 \mathrm{~m} / \mathrm{s}$ for deeper reflections near the bedrock boundary. 


\section{RESULTS}

Figure 2 shows two intersecting stacked cross sections extracted from the 3-D data set, one running nearly parallel and one nearly perpendicular to the dominant flow direction of the former glacier. Due to the dominant reflection frequencies of $>100 \mathrm{~Hz}$, a vertical resolution of 3 $-6 \mathrm{~m}$ has been achieved. The crossover point of the two profiles is located at the drillhole. On the basis of information extracted from this drillhole, the quasi-continuous reflection zone at 20 to $30 \mathrm{~ms}$ is interpreted as the interface between near-surface lacustrine silts/clays and underlying glacial tills. The series of undulating flat or slightly dipping reflections in the top $-75 \mathrm{~ms}$ can be related to shallow intercalated units of sand/gravel and silt/clay. Less reflective units in the deeper parts of the sections are representative of monotonously fine grained material (probably a deeper sequence of lacustrine silts/clays) at the base of the valley. Although bedrock has not been drilled in the survey area, it is probably represented on the E-W profile by the reflection zone dipping from $125 \mathrm{~ms}$ at CMP 120 eastward to $175 \mathrm{~ms}$ at CMP 260.

\section{REFERENCES}

Büker, F., Horstmeyer, H., and Green, A.G., 1996, 3-D high-resolution seismic reflection imaging of glacial sediments in the Swiss Molasse Basin: Proc. $2^{\text {nd }}$ Meet. European Section Environ. Engin. Geophys. Soc., Nantes, France, Sept. 2-5, 39-42.

Büker, F., Green, A.G., and Horstmeyer, H., 1997, Shallow seismic reflection study of a glaciated valley: submitted to Geophysics.

Lanz, E., Pugin, A., Green, A.G. and Horstmeyer, H., 1996. Results of 2- and 3-D high-resolution seismic reflection surveying of surficial sediments. Geophys. Res. Lett., 23, 491-494.

Robertson, J.O.A., Holliger, K., and Green, A.G., 1996. Source-generated noise in shallow seismic data. European J. Environ. Engin. Geophys., 1, 107-124.

Table 1: Processing Operations

\begin{tabular}{|c|}
\hline Data Conversion \\
\hline Geometry \\
\hline Editing \\
\hline First Break Picking \\
\hline Refraction Statics \\
\hline Scaling \\
\hline Spectral balancing, Deconvolution, $\tau$-p Filtering \\
\hline Bandpass Frequency Filtering \\
\hline Top mutes \\
\hline Velocity Analyses \\
\hline NMO corrections \\
\hline Residual Statics \\
\hline Stack \\
\hline
\end{tabular}

Figure 1: (a) Raw data gather dominated by low frequency guided waves and ground-roll. Shallow reflections at 30 to $70 \mathrm{~ms}$ become evident after (b) spiking deconvolution and bandpass filtering or (c) spectral balancing. (d) as for (c) after application of top mute.

Figure 2: $\quad$ Example of (a) an in-line stack section and (b) a cross-line stack section extracted from the 3-D data cube running approximately perpendicular and parallel, respectively, to the general flow direction of the former glacier. Sections intersect at the $72 \mathrm{~m}$ deep drillhole that penetrated units of clay, sand and gravel. 


\section{Trace Number}
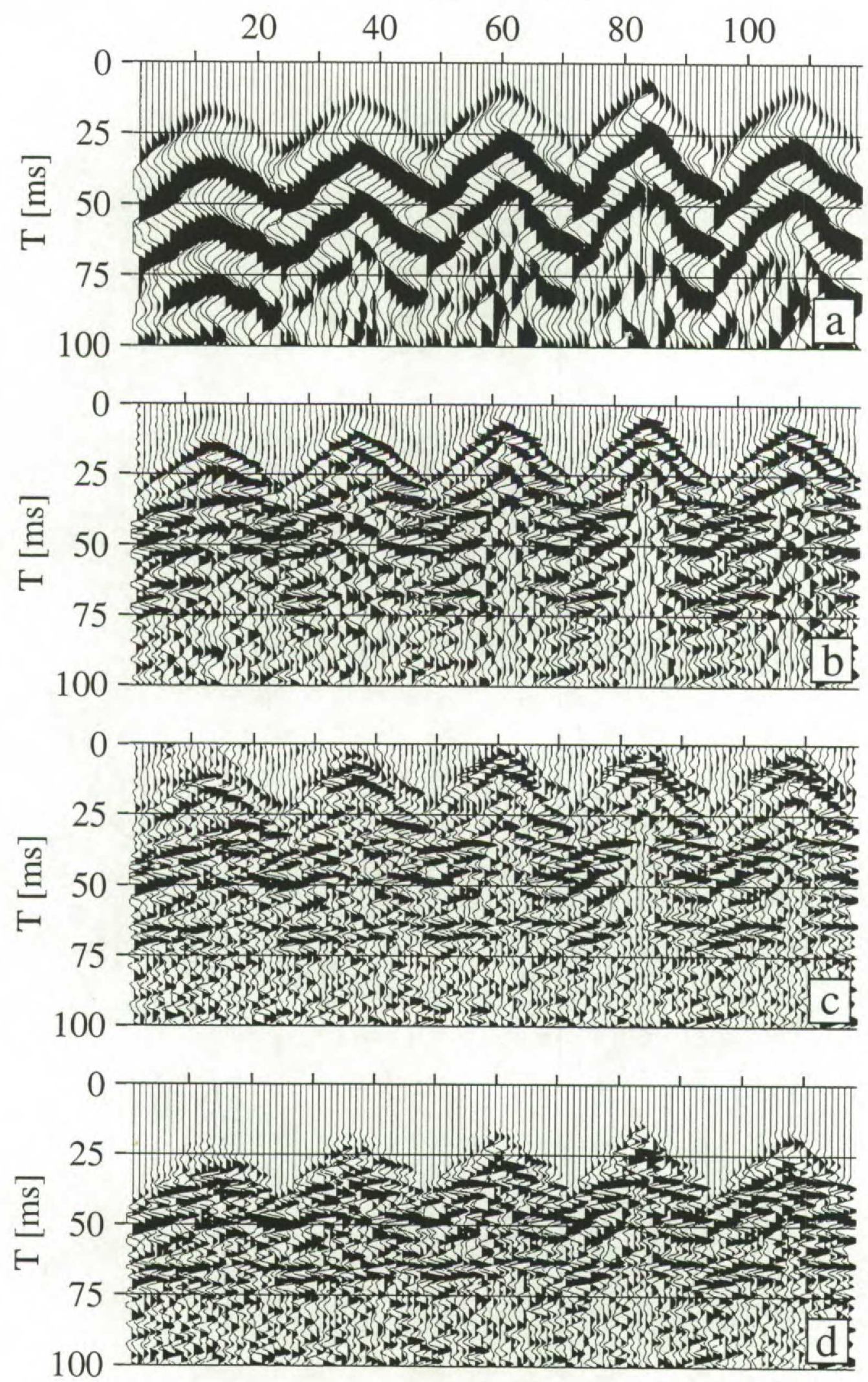


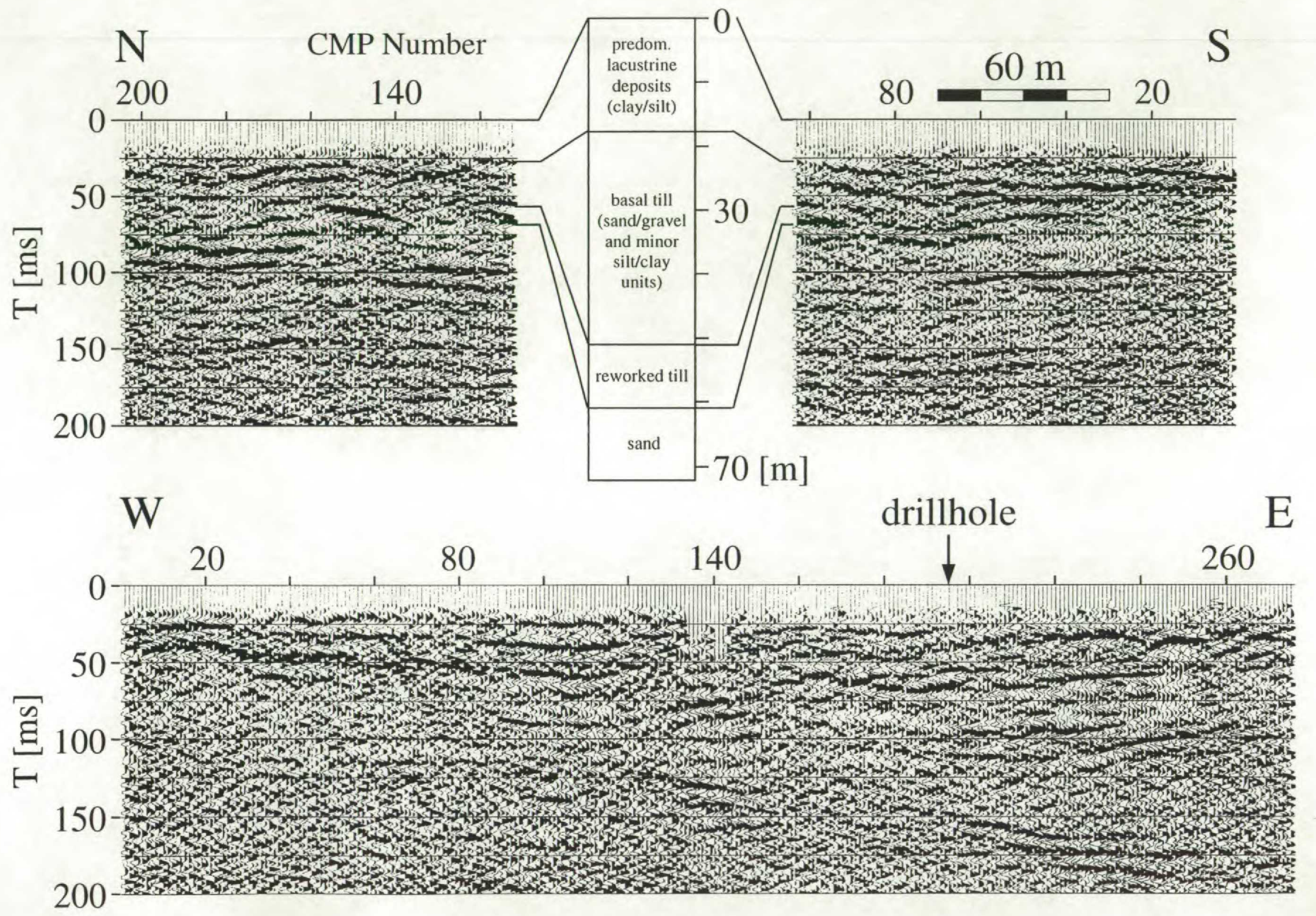

